\title{
A Hungria/sertão de Guimarães Rosa
}

\author{
Eneida Maria de Souza ${ }^{1}$
}

\begin{abstract}
This essay focuses on the relationship between the writer/diplomat Guimarães Rosa and the Hungarian imaginary from the interpretation produced by a Brazilian gaze in the face of the foreign culture. Rosa's preface to the Hungarian tales translated into Portuguese by Paulo Rónai (published in 1957) reveals the poetic sensibility of the writer in building bridges between cultures, at first distant from each other. The text shows Rosa's signature, for it presents a reading of Hungarian culture by means of an approximation to its own conception of what the literary is, its nature being at the same time cosmopolitan and local. The relationship between Rosa and Paulo Rónai falls under the scope of the poetic/translational construction, which was already worked out, during his stay in Hamburg as Vice Consul (1938/42), in a heteroclite blend of languages and cultures. The meeting of the authors/ translators allowed the cross-reading of Brazil and Hungary.
\end{abstract}

Keywords: Guimarães Rosa; Paulo Rónai; Hungary; translational poetic; backcountry.

Resumo: Este ensaio se concentra na relação entre o escritor/diplomata Guimarães Rosa e o imaginário húngaro, a partir da interpretação realizada pelo olhar brasileiro frente ao estrangeiro. O prefácio de Rosa aos contos húngaros traduzidos para o português por Paulo Rónai (publicado em 1957) evidencia a sensibilidade poética do escritor em estabelecer pontes entre culturas, a princípio distantes entre si. O texto tem a assinatura de Rosa, por apresentar uma leitura da cultura húngara de forma a aproximá-la de sua própria concepção literária, de natureza ao mesmo tempo cosmopolita e local. A relação de Rosa com Paulo Rónai se inscreve no âmbito da construção poética/tradutória do escritor, o qual já se exercitava, na sua estada em Hamburgo como vice-cônsul (1938/42), na mescla heteróclita entre línguas e culturas. $\mathrm{O}$ encontro dos autores/tradutores possibilitou a leitura cruzada entre Brasil e Hungria.

Palavras-chave: Guimarães Rosa; Paulo Rónai; Hungria; poética tradutória; sertão.

Para mim, Cordisburgo sempre foi uma Europa em miniatura. Amamos a Europa como, por exemplo, se ama uma avó.

Guimarães Rosa

Paulo Rónai chega ao Brasil como imigrante judeu em 1941, graças ao visto especial concedido pelo governo brasileiro por sua contribuição à difusão da cultura nacional. Organizador, em Budapeste, da tradução de uma Antologia de poetas brasileiros, em 1939,

1 Professora Titular de Teoria Literária - Universidade Federal de Mindas Gerais. 
mantém contato com Ribeiro Couto, poeta e diplomata na Holanda, para obter informações sobre alguns poemas a serem publicados na referida Antologia. Por sua intervenção diplomática, Ribeiro Couto contribui para a libertação de Rónai do campo de trabalho no qual se encontrava. Ao exercer atividades de tradutor, professor e filólogo, o ensaísta permanece no Brasil até sua morte, em 1990, cumprindo o papel de divulgador da literatura brasileira na Europa e da estrangeira no país. Torna-se um dos maiores representantes dos estudos de literatura comparada entre nós, ao lado de Otto Maria Carpeaux, outro exilado europeu que se instala no país nos anos 40. Pertencer à literatura universal é o que concede a Rónai a oportunidade de estabelecer pontes entre culturas e de ampliar as relações literárias entre obras de nacionalidades diversas. O primeiro encontro de Rónai com Rosa diplomata se dá de forma inusitada, ao ser chamado ao Itamaraty, após o término da Segunda Grande Guerra, para conversar com o Conselheiro Guimarães. Pela coincidência dos nomes, o escritor foi confundido com outro membro da Embaixada, equívoco mais tarde refeito. Reproduzo o depoimento do tradutor concedido em entrevista a Nelson Ascher e Alcino Leite Neto:

Meu encontro com Guimarães Rosa foi muito interessante. Durante a guerra, tinha pedido vistos de entrada no Brasil para minha mãe e minhas irmãs. Quando acabou a guerra, fui chamado ao Itamaraty para falar com o Conselheiro Guimarães. Encontrei esse Conselheiro que me recebeu muito rispidamente e me mandou embora. Eu não entendi porque me chamaram. Aí alguém disse: "você deve ter falado com o Guimarães errado. O secretário do ministro é Guimarães Rosa, que é uma pessoa muito cortês" Ai eu voltei e efetivamente fui recebido com muita cortesia. Meu pedido foi atendido, a minha família pôde entrar no Brasil. E assim tive os primeiros contatos com o Rosa, que eram meramente funcionais.

Neste primeiro contato formal, evidencia-se a posição política de Rosa iniciada em Hamburgo, diante da perseguição judaica, quando exercia a função de cônsul-adjunto nesta cidade de 1938 a 42. A liberação de vistos aos judeus concedidos pelo Consulado contou com a ação do escritor e de sua segunda mulher, Aracy Moebius de Carvalho, esta responsável pela seção de passaportes. É de extrema importância a leitura dos originais do Diário de guerra de Rosa, escrito durante o exercício como cônsul-adjunto na Alemanha, em que descreve a perseguição nazista aos judeus e o ambiente amedrontador aí criado durante a guerra. A publicação do texto, após editoração realizada por Reinaldo Marques, Georg Otte e por mim, encontra-se ainda censurada pela família.

A primeira aproximação entre Rosa e Rónai estaria marcada pelo gesto político, de ordem burocrática, mas de extrema importância para o destino do tradutor no país. A cortesia desse encontro poderia ter ficado no âmbito da formalidade se, pouco tempo mais tarde, em 1946, o ensaísta não se manifestasse sobre Sagarana, sob forma de resenha, assim que o livro foi lançado. A partir dessa relação de ordem literária, os laços entre dois entusiastas das línguas e das linguagens iriam se fortalecer ao longo dos anos. Filólogo e escritor cultivavam o amor da língua, não se restringindo aos idiomas maternos, mas se expandindo por outros de procedências diversificadas. Rónai ocupará na divulgação da obra de Rosa lugar de destaque, prefaciando em 1962 Primeiras estórias e sendo responsável pela publicação póstuma de Ave, palavra e Estas estórias. A prática tradutória, de âmbito literal em Rónai, é assumida metaforicamente por Rosa, na sua poética revolucionária e transgressora, ao condensar e inventar palavras de origens diferentes. Seu processo criador se alimentava da paixão pelo cruzamento de línguas e culturas e pela ruptura de fronteiras entre nacional e estrangeiro. Para um terceiro encontro entre eles, a cultura húngara funcionará como mediadora, quando Rónai publica a Antologia do conto húngaro, em 1957.

Solicitado a escrever o prefácio da Antologia, em 1956, Rosa já havia publicado Corpo de baile e Grande sertão: veredas. Com o titulo sugestivo de "Pequena palavra", o texto 
introdutório não se restringe a comentar o teor dos contos traduzidos por Rónai, mas se constrói de forma a valorizar a cultura húngara no que ela possui de heterogênea e de original. O escritor brasileiro irá pautar seu ensaio por descrições da história e da geografia húngaras, na busca de seus laços orientais e de sua conformação como país ocidental. Não deixa escapar a preocupação com a língua, detendo-se em explicações e exemplos de um idioma que conhecia e do qual muitas vezes se valeu na construção e invenção de vocábulos. Considerada uma língua em movimento e de alto grau de estranheza para falantes estrangeiros, ela mantém, segundo o escritor, e em consonância com o imaginário de Grande sertão: veredas, um pacto com o diabo. E por esta razão, seu olhar para esta cultura revela-se contaminado pela impureza que preside as misturas.

Donde bem, por essas e por outras, contam que Carlos V, que desde muito menino teve de estudar uma porção de idiomas, por quantas e tantas terras e povos em que reinar, costumava dizer que: o espanhol era para falar com os reis, o italiano com a mulher amada, o francês com o amigo, o holandês com serviçais, o alemão com os soldados, o latim com Deus, o húngaro...com o diabo.

Essa língua diabólica e fruto da herança dos ancestrais nômades vindos da Ásia, gerados nas franjas da Mongólia e cavalgando nas planícies, exerce grande fascínio no escritor das gerais, usurpador de outros idiomas e inventor de uma linguagem própria. Começam assim a se desenhar as seduções provocadas por essa cultura, dotada de força musical e de traço dançarino de seu povo, herança da índole cigana e nômade de seus primeiros habitantes e dos atrativos sensoriais, em que se destacam os cheiros e gostos de sua peculiar culinária. A associação entre culturas se efetiva em razão da prática transculturadora por meio da qual a poética rosiana se constrói. As descrições da configuração geográfica húngara ressaltam a planura, as estepes e o semi-sertão, povoados de pastores seminômades, peões de cavalos, paisagem que se descortina como se estivesse saindo das páginas do sertão brasileiro. Essa confluência de costumes e lugares do imaginário rosiano reveste-se igualmente de traços de sua linguagem poética, no sentido de estar transportando, traduzindo literariamente os gerais para a sedutora terra dos ciganos.

Dessa mescla entre oriente e ocidente resulta uma população de complexa configuração étnica, o que a torna bastante peculiar na Europa e transforma a Hungria num país dominado pelas contradições: o charme e o feitiço do povo oriental, este dotado de espírito libertário e guerreiro, ao lado do requinte e da aristocracia de sua sociedade, qualidades que confirmam o elo com o ocidente:

De Budapeste - a "Rainha do Danúbio"," sobre as duas margens, divididas, dupla, una, Buda+Pest, importante praça comercial entre as Europas, celebremente bela, com sua situação única como feição urbana e arredores - direi que é 'virilmente' feminina? Já se sente o Oriente, mas é a essência oriental ocidentalmente civilizada, supercivilizada, requintadíssima.

Esse encantamento é visível no texto de Rosa, que se manifesta atento às descrições detalhistas e às opiniões muito particulares. Lugar este vivido ficcionalmente, com a ajuda de leituras e com a experiência de ter servido como diplomata em Hamburgo e em Paris, onde teve a oportunidade de conviver com várias facetas da cultura europeia, além de revelar sempre o interesse pelas culturas orientais. Trata-se de um texto construído com a assinatura do romancista dos sertões, acostumado a transpor fronteiras e a traduzir sua cultura com a ajuda de outras, de inventar o olhar estrangeiro no seu próprio país e de transportar o olhar nacional para fora. De índole viajante e cigana, Rosa encontra-se cada vez mais entregue às bruxarias e aos apelos do demo, reduplicando-se em personagem e revivendo as aventuras de Riobaldo. O tom documental e ao mesmo tempo ficcional do prefácio insiste no elogio e no medo por esta paisagem que penetra gradativamente na sua escrita fabular. 
A predileção de Rosa por personagens marginalizados pela sociedade, como os loucos ou os ciganos, recebe tratamento especial em sua obra, por representarem, os últimos, a clandestinidade, o nomadismo, o desenraizamento e a ruptura da ordem socialmente estabelecida. Os ciganos, povo de origem oriental, se deslocaram para o ocidente e nesse processo migratório se espalharam pelo mundo inteiro, vivendo em bandos e não se fixando em lugar nenhum. São até hoje alvo de perseguição, amaldiçoados e associados a comportamentos negativos, como a astúcia, trapaça e a atos de vandalismo e roubo. Ao lado dessa índole subversiva, o que igualmente cativou Rosa foi sua sensibilidade romanesca, associada ao poético, à música e à dança, qualidades apontadas no prefácio à tradução dos contos húngaros.

Os exemplos encontrados na ficção de Rosa comprovam o entusiasmo pela presença cigana na Hungria, o que irá cada vez mais se aproximar de seu imaginário. Manuel Fulô, personagem do conto "Corpo fechado", de Sagarana, aprendeu com os ciganos a lidar com os cavalos, trapaceando-os depois; Nhorinhá em Grande sertão: veredas, de origem cigana, é a prostituta com quem Riobaldo se relaciona; em Tutameia, a presença de três contos, "O outro ou o outro" Faraó e a água do rio" e "Zingaresca", explora o mundo fabuloso e fascinante protag,onizados pelos amantes da música e da dança. Narra-se a transformação da vida pacata dos habitantes da fazenda com a chegada dos ciganos, assim como a descoberta de suas trapaças e a instauração do desequilíbrio como ameaça à ordem e à vida regrada do sertão. Essa desordem propicia o despertar de desejos recalcados das personagens, o convite ao sonho e ao devaneio. O colorido das roupas e o inusitado de suas ações possibilitam a criação do clima de fantasia vivenciado pelas mulheres do conto "Faraó e a água do rio". Com a partida dos itinerantes restaura-se a normalidade e a vida retorna ao que era antes: "Os ciganos eram um colorido. (...) Recordavam motes: - Vós e as flores ... - em impo, finaldo entoou Florflor, o Sonhado Moço. Vinha de um romance, qual que se suicidado por paixão, pulando no rio, correntezas o rodavam à cachoeira... -Sinhalice caraminholava."

Com o olhar de ficcionista, Rosa se familiariza com os contos coletados por Rónai, pela sua expressão nitidamente popular e lendária, apropriados do imaginário rural da Hungria, com suas histórias fantásticas, povoadas de reis, ciganos, animais e figurações do diabo ou da morte. Os textos remontam a narrativas singelas e pitorescas, com forte tendência pelo mistério, a magia e o sobrenatural. A leitura dos contos propicia ao prefaciador não só a necessidade de registrar afinidades com autores clássicos europeus como semelhanças temáticas no tratamento do material literário. Na investida tradutória de Rosa, as distâncias temporais e espaciais são esquecidas graças ao encontro heterogêneo e simultâneo das literaturas. A simbiose do escritor/ensaísta com a cultura húngara resulta do processo de transmigração linguística e cultural, pelo seu diálogo com as mais distantes e distintas civilizações. No interesse sempre obsessivo pelo aprendizado das línguas, pelas anotações em cadernos durante viagens e passeios, o autor desempenha o papel de enciclopedista e diletante, ao lado da atenção pelos detalhes e minúcias dos acontecimentos observados. No final do prefácio, reitera o papel do leitor que se investe de mediador transcultural na busca de reflexos e ressonâncias.

Vão lê-los, todos, porém, e enfim. E vão ver o que eles trazem, mais. O obtido retrato da Hungria; a presença, pura poética, mas mesmo sofrentemente prosaica, de uma gente qual que padece e goza, se atonta nesses enigmas do viver, mistura desilusões e esperanças, aguenta o cada dia - feito nós, igualzinho, feito a gente de toda parte. Uma Hungria, pois, muito mais próxima do que a de um turista vê em apressada superfície, do que a que um diletante colhe de escolhidos reflexos.

A maioria dos autores da Antologia pertence ao século XX, de cujas biografias constam serem exilados políticos, vítimas da perseguição judaica ou de ideologias, ao lado de escritores tradicionais que se dedicam a cantar sua terra no que ela representa de mais 
tradicional e popular. Entre os poucos conhecidos por mim, destaca-se Sándor Márai, escritor de sucesso internacional, que se autoexilou por não concordar com o governo comunista, realizando promissora carreira fora de seu país. No Brasil seus livros foram muito traduzidos, destacando-se As brasas, publicado pela Companhia das Letras em 1999. Nas palavras de Rónai, Márai é descrito da seguinte forma: "seu gênero preferido, uma criação pessoal, a meio caminho entre o essay inglês e a nossa crônica, deliciou um público reduzido e culto, que lhe apreciava os dotes de analista agudo, a grande cultura, o estilo amaneirado (...)." No texto escolhido pelo tradutor, "O criminoso", evidencia-se a tendência poética de Márai, pautada pela reflexão sobre a literatura, na qual se coloca como personagem, atitude metaliterária a ser cultuada nos outros livros de sua autoria. No conto selecionado, o autor desconstrói as regras do gênero policial, inserindo perguntas ao longo da narrativa e mantendo o diálogo irônico com o leitor. Esse texto não é mencionado por Rosa no prefácio, ocasião em que elogia e analisa vários contos escolhidos entre os melhores. Talvez pelo recurso à metalinguagem? Ou por se desinteressar Márai pelo ambiente rural e mágico vivamente explorado nos demais escritores?

A fascinação de Rosa pela cultura húngara é contaminada pelas analogias que estabelece com o embevecimento e a ameaça diabólica do sertão brasileiro, o perder-se diante das tentações. A escrita registra o encontro entre várias modalidades de vivência cultural, traço inconfundível de Rosa, pela mistura de tempos e espaços como se fizessem parte do jogo fabular. A Hungria é ao mesmo tempo lugar sedutor e perigoso, como se transfigurasse num texto dominado por forças obscuras, atraentes e amedrontadoras. A ameaça de se perder em Budapeste se convertia em prazer e medo, sentimento contraditório que bem define o encantamento provocado pelos sortilégios e as tentações:

Dizia-me um diplomata brasileiro, que servia, antes da última guerra, em Budapeste, querer sair urgente de lá, porque tinha medo, medo de perder-se, de ceder demais às vantagens da vida. De verdade, a gente ali se sentia imediatamente exposto a um encanto bruxo, a cento de sortilégios. O clima amparante, o ar bom, o bom vinho, a comida temperada gostosa, a amabilidade extrema da gente, os amigos facilmente feitos, a hospitalidade larga, o amor do luxo e do fausto, oriental, as maravilhosas mulheres, o visível ser das Danúbiades.

A proposta poética de Rosa está devidamente exposta neste prefácio, ao se considerar, como em outras situações, um escritor brasileiro, por fugir da pecha de regionalista e se libertar dos modelos estrangeiros como matriz de influências. O dilema da dependência cultural não entra como reflexão para a interpretação da cultura brasileira, para sua visão literária. Entre o fora e o dentro instaura-se a mediação pela leitura que traduz horizontalmente as culturas e inscreve um terceiro termo anulador das oposições. Entregar-se ao outro é narrá-lo sob a forma do duplo, sem que as partes sejam absorvidas entre si, sem que se dilua o local no global, mas que estabeleçam trocas e convivência mútua. A despersonalização do narrador permite que se produza a voz em terceira pessoa, distanciada de espelhismos e esquecida dos lugares de origem. Ciganos da Hungria? Ciganos do sertão? Reside aqui a metaforização de uma poética textual, na figura desses personagens que trapaceiam e invertem o sentido de propriedade, pelo seu espírito nômade, aventureiro e transgressor.

A definição de Rosa do exercício deglutidor de sua literatura é transmitida num ensaio de Haroldo de Campos, em que reproduz a enunciação distanciada do escritor ao se referir a si próprio em terceira pessoa. Trata-se de uma prática deglutidora que se aproxima e se afasta da antropofagia modernista oswaldiana, por não utilizar o código antropocêntrico, mas o animal, presente na lição de sabedoria retirada do comportamento da ostra. Descarta, por conseguinte, o espírito guerreiro e o gesto de vingança em relação à cultura estrangeira, 
assumindo o local como parte integrante dos empréstimos globais. Permanece o sentimento de alteridade e a produção de resultados literários retirados do duplo movimento do dentro e do fora. Não se pautando pela estética modernista, o escritor relê a cultura estrangeira com a metáfora da ostra, da pérola - a beleza e a perfeição - que daí se extrai e se impõe como nova abertura para a literatura moderna. No ensaio de Campos, Rosa assim se autodenomina:

"Dizem que Rosa é regionalista" - e dava uma risadinha típica dele. "Ah! Eu me divirto muito com isso... Porque dizem que eu fiz uma paisagem, um crepúsculo mineiro, e não é nada de crepúsculo mineiro, é um crepúsculo que eu vi na Holanda, misturei com uma coisa que eu vi em Hamburgo, com coisas de Minas, misturei tudo aquilo e joguei lá - e as pessoas dizem que eu estou fazendo uma cena do interior de Minas, e eu estou fazendo um omelete ecumênico. O Rosa é como uma ostra: projeta o estômago para fora, pega tudo que havia pegado, de todas as fontes possíveis, e introjeta de novo no estômago, mastiga tudo aquilo e produz o texto.

Com essa declaração, conclui-se que o processo criativo de Rosa vincula-se à prática cultural como prática tradutória, assumida tanto por Rónai quanto por si próprio. Mas o que os diferencia é a proposta de infidelidade do tradutor diante do original, defendida pelo escritor como "fecundante corrupção das nossas formas idiomáticas de escrever", ao contrário de Rónai, que, com isenção da língua materna, realizou, segundo a opinião de Rosa, um "abrasileiramento radical, um brasileirismo generalizado" no seu trabalho de tradução. No entanto, o escritor preferiria que o tradutor ousasse um pouco, operando uma "tratação num arranjo mais temperado à húngara", no sentido de enriquecer o idioma nacional com pitadas dessa "língua do diabo". A reflexão de Benjamin no ensaio "A tarefa do tradutor", de 1923, é aqui vislumbrada, quando Rosa defende a ampliação e o aprofundamento da língua materna com a ajuda da língua estrangeira. Graças ao gesto de sobrevida, a tradução realimenta o original, torna simultânea a experiência e concorre para o esclarecimento da poética transculturadora e ecumênica do escritor. A sobrevida do original justifica-se também pelo "ressaibo e o vinco" retidos nos vestígios da língua estrangeira no gesto tradutor. Rosa traduz Rónai e introjeta no texto húngaro traços de uma brasilidade flutuante:

A mim, confesso-o, talvez um pouquinho, quem sabe, até agradasse também a tratação num arranjo mais temperado à húngara, centrado no seio húngaro, a versão estreitada, de vice-vez, contravernacular, mais metafrástica, luvarmente translatícia, sacudindo em suspensão vestígios exóticos, o espacioso de traços hungarianos, hungarinos - o ressaibo e o vinco - como o tókai, que às vezes deixa um sobregosto de asfalto. Mesmo à custa de, ou - franco e melhor falando - mesmo para haver um pouco de fecundante corrupção das nossas formas idiomáticas de escrever.

\section{Referências}

BENJAMIN, Walter. A tarefa do tradutor. Tradução de Karlheinz e outros. In: A tarefa do tradutor, de Walter Benjamin. Belo Horizonte: Viva Voz; FALE/UFMG, 2008. CAMPOS, Haroldo de. Metalinguagem e outras metas. 4. ed. São Paulo: Perspectiva, 1992. In: COSTA, Ana Luiza Martins. Veredas de Viator. Cadernos de Literatura Brasileira. João Guimarães Rosa. São Paulo, Instituto Moreira Salles, n. 20 e 21, 2006. RÓNAI, Paulo. A arte de contar em Sagarana. Rio de Janeiro: Diário de Notícias, 11 jul. 1946.

RÓNAI, Paulo. Antologia do conto húngaro. (Seleção, tradução, introdução e notas). Rio de Janeiro: Civilização Brasileira, 1957. 
RÓNAI, Paulo. Faz 50 anos que o tradutor e ensaísta chegou ao Brasil. Entrevista concedida à Folha de S. Paulo a Nelson Ascher e Alcino Leite Neto. São Paulo: 27 abr. 1991.

ROSA, Guimarães. Faraó e a água do rio. In: Tutameia. Terceiras estórias. Rio de Janeiro: José Olympio, 1967.

ROSA, Guimarães. Guimarães Rosa por ele mesmo. O escritor no meio do redemunho. In: Cadernos de Literatura Brasileira. João Guimarães Rosa. São Paulo: Instituto Moreira Salles, n. 20 e 21, p. 79, 2006.

ROSA, Guimarães. Pequena palavra. In: RÓNAI, Paulo. Antologia do conto húngaro. (Seleção, tradução, introdução e notas). Rio de Janeiro: Civilização Brasileira, 1957. SOUZA, Eneida Maria de. Rosa entre duas margens. Revista de Cultura Margens/ Márgenes. Belo Horizonte, p. 12-19, 2002.

SOUZA, Eneida Maria de. De animais e de literatura. Rosa, Kafka, Coetzee. Revista Aletria. Belo Horizonte, v. 21, n. 3, p. 83-90, 2011.

SOUZA, Eneida Maria de. O escritor vai ao Zoológico. In: BORGES, M. E. (Org.) Pensarlescrever o animal. Ensaios de zoopoética e biopolítica. Florianópolis: Editora da UFSC, 2011. p. 245-253.

SOUZA, Eneida Maria de. Rosa residual. In: MIRANDA, Wander Melo; SOUZA, Eneida Maria de. (Orgs.). Crítica e Coleção. Belo Horizonte: Editora UFMG, 2011. p. 58-69. 